\title{
Xây dựng đường cong cường độ-thời đoạn-tần suất mưa hướng đến thiết lập bản đồ ngập lụt cho khu vụ̣c bán đảo Cà Mau
}

\section{Hồ Công Toàn ${ }^{1}$, Đặng Trường An ${ }^{1^{*}}$}

${ }^{1}$ Trường Đại học Khoa học Tự nhiên, ĐHQG-HCM; hocongtoanhdh@gmail.com; dtan@hcmus.edu.vn

*Tác giả liên hệ: dtan@hcmus.edu.vn.com; Tel.: +84-909719878

Ban Biên tập nhận bài: 08/4/2021; Ngày phản biện xong: 18/5/2021; Ngày đăng bài: $25 / 7 / 2021$

Tóm tắt: Trong những năm gần đây, các hiện tượng mưa với cường độ lớn xuất hiện ngày càng thường xuyên tại khu vực bán đảo $\mathrm{Cà} M a u(B Đ C M)$ gây ngập cục bộ và làm ảnh hưởng đến đời sống của người dân trong khu vực. Theo báo cáo của Bộ Tài Nguyên và Môi Trường, mưa tại khu vực $\mathrm{BĐCM}$ có xu hướng gia tăng về cường độ và chu kỳ lặp lại trong tương lai như hệ quả của biến đổi khí hậu $(\mathrm{BĐKH})$. Mưa với cường độ lớn có xu hướng tăng sẽ góp phần làm tình trạng ngập lụt cục bộ tại các khu vực có địa hình thấp và hệ thống tiêu thoát nước kém trầm trọng hơn. Việc chủ động phòng tránh các ảnh hưởng bất lợi từ các sự kiện mưa gây ngập đối với đời sống người dân, phân tích chu kỳ lặp lại của một cơn mưa gây ngập lụt là rất cần thiết. Chính vì vậy, mục tiêu của nghiên cứu là: a) xác định chu kỳ lặp lại của một sự kiện mưa cực đoan cho khu vực $\mathrm{BĐCM}$ bằng phầm mềm CumFreq và $b$ ) hướng đến xây dựng bản đồ ngập lụt dựa trên dữ liệu được tính toán từ đường cong cường độ-thời đoạn-tần suất (IDF) mưa góp phần hỗ trợ chủ động phòng tránh nguy cơ gây ngập lụt do mưa cũng như góp phần thích ứng với BĐKH cho khu vực BĐCM.

Từ khóa: Ngập lụt; Vùng trũng; Mưa cực đoan; Nước biển dâng; Bán đảo Cà Mau.

\section{Mở đầu}

Theo báo cáo của IPCC-Ủy Ban Liên Chính Phủ về BĐKH [1], BĐKH toàn cầu sẽ dẫn đến mực nước biển tại nhiều quốc gia trên thế giới có xu hương tăng. IPCC cũng đánh giá rằng, mưa tại nhiều khu vực trên thế giới đang có xu hướng tăng, thời đoạn và chu kỳ lặp lại của các sự kiện mưa cực đại cũng được nhận định đang gia tăng dưới tác động của $\mathrm{BĐKH} \mathrm{và}$ điều này sẽ ảnh hưởng đáng kể đến đời sống kinh tế-xã hội toàn cầu [2-3]. So với các yếu tố khí hậu khác, mưa được đánh giá là yếu tố quan trọng có ảnh hưởng trực tiếp đến nhiều mặt của đời sống nhân loại $[2,4-5]$. Dưới ảnh hưởng của $\mathrm{B} Đ K H$, chu kỳ lặp lại và cường độ của các sự kiện mưa lớn, mưa cực đoan hay mưa trong bão xảy ra ở Việt Nam được nhận định có xu hướng gia tăng và tiềm ẩn các rủi ro cho đời sống nhân dân, gây nhiều tổn thất về cơ sở hạ tầng và tính mạng con người, tác động xấu đến môi trường [2, 6-7].

Nhận thức được tầm quan trọng từ hậu quả do các sự kiện mưa lớn gây ra đối với nhiều mặt của đời sống nhân loại dưới ảnh hưởng của $\mathrm{B} Đ K H$ trong những năm gần đây. Nhiều nghiên cứu về mưa to, mưa cực đoan gây ngập lụt cục bộ các khu đô thị, các thành phố lớn trên thế giới đang nhận được sự quan tâm từ các nhà khoa học. Ở Nigeria [8] đã tiến hành xây dựng đường cong IDF mưa cho khu vực Makurdi. Trong nghiên cứu này, nhóm thực hiện phân tích dữ liệu lượng mưa khu vực Makurdi Metropolis, Bang Benue, Nigeria từ 01/1982 đến 12/1991 bằng ba hàm phân phối xác suất là Gumbel, Weibull và Gringorton. Kết quả 
phân tích cho thấy hàm phân phối xác suất Gumbel là lựa chọn phù hợp để xây dựng bộ thông số cho xây dựng đường cong IDF mưa cho khu vực nghiên cứu. Ở Pháp, năm 2016 [9] đã tiến hành nghiên cứu diễn biến theo thời gian của mức độ dễ bị tổn thương do lũ lụt của hai thành phố Besançon và Moissac. Cả hai sự kiện lũ đã xảy ra năm 1910 và 1930 được đánh giá là những sự những sự kiện nghiêm trọng nhất được ghi nhận ở Pháp trong thế kỷ 20 . Các tác giả báo cáo rằng cường độ và mức độ nghiêm trọng của hai sự kiện mưa gây ngập lụt và những thiệt hại do chúng gây ra là vô cùng lớn. Các tác giả đã khẳng định việc phân tích các dữ liệu mưa lịch sử cho phép thành lập bản đồ cảnh báo các rủi do tiềm ẩn cho các khu vực dễ bị ảnh hưởng bởi lũ lụt. Năm 2014, [10] đã tiến hành nghiên cứu đánh giá ảnh hưởng của BĐKH đối với lượng mưa cực đoan cho khu vực Địa Trung Hải. Nhóm nghiên cứu đã sử dụng 114 chuỗi số liệu lượng mưa quy mô ngày giai đoạn 1951-1999 đại diện cho khí hậu giai đoạn hiện tại và 2000-2099 đại diện các kịch bản tương lai $\mathrm{A} 1 \mathrm{~B}, \mathrm{~A} 2$ và $\mathrm{B} 2$. Kết quả chỉ ra rằng, các yếu tố $\mathrm{BĐKH}$ trung bình được tính toán từ lượng mưa hàng ngày tăng với tất cả các chu kỳ lặp lại trong giai đoạn khí hậu hiện tại và cả các kịch bản khí hậu tương lai. Nghiên cứu cũng báo cáo rằng, những năm cuối thế kỷ 21 dưới kịch bản $\mathrm{A} 1 \mathrm{~B}, \mathrm{~A} 2$ và $\mathrm{B} 2$, cường độ mưa thu được được với khoảng thời gian phản hồi từ 10 đến 500 năm sẽ vượt đường cong IDF tại khu vực Barcelona từ $3 \%$ đến $14 \%$.

Trong những năm gần đây, quá trình công nghiệp hóa hiện đại hóa ngày càng phát triển nhanh ở một số đô thị lớn của Việt Nam, chính điểu này cũng gây áp lực lên cơ sở hạ tầng (hệ thống thoát nước, tiêu thoát nước thủy lợi, đường giao thông, ...). Hệ quả là nhiều đô thị lớn thường bị ngập do mưa. Để giải quyết tình trạng trên, nhiều nghiên cứu về xây dựng đường cong IDF mưa, một phương pháp thường được áp dụng trong các nghiên cứu về quy hoạch đô thị và thiết kế các công trình dân dụng đã được thực hiện. Cụ thể, [11-12] đã tiến hành nghiên cứu biến đổi không gian của mưa cực trị và xây dựng đường cong IDF mưa cảnh báo ngập lụt cho khu vực TP. HCM. Trong công trình nghiên cứu, [11] đã sử dụng chuỗi dữ liệu mưa cực trị của các trạm thuộc khu vực TP. HCM trong giai đoạn 1980-2014. Nghiên cứu tiến hành xây dựng đường cong IDF mưa dựa trên hàm phân bố xác suất $(\mathrm{GEV})$. Kết quả nghiên cứu chỉ ra rằng, mưa lớn là nguyên nhân chính gây ngập lụt cho khu vực TP. HCM. Trong khi, [12] đã xây dựng đường cong IDF mưa dựa trên hàm phân phối Log-Pearson giai đoạn hiện tại 1986-2005 và các kịch bản $\mathrm{BĐKH} \mathrm{tương} \mathrm{lai.} \mathrm{Kết} \mathrm{quả} \mathrm{nghiên} \mathrm{cứu} \mathrm{cho} \mathrm{thấy,} \mathrm{cường} \mathrm{độ} \mathrm{các}$ trận mưa lớn cùng với các thời đoạn và các thời kỳ khác nhau đều ghi nhận xu hướng tăng từ 11-69\%. Một nghiên cứu đánh giá sự biến động lượng mưa theo thời gian cho vùng Đông Bắc Việt Nam được tiến hành bởi [13] thông qua xây dựng đường cong IDF mưa hỗ trợ xây dựng tần suất lũ thiết kế cho hệ thống giao thông. Nhóm nghiên cứu đã báo cáo rằng phương pháp tính toán tần suất lũ thiết kế dựa trên đường cong IDF mưa là phù hợp và triển vọng áp dụng cho những khu vực khác của Việt Nam. Gây đây, năm 2018 [14] đã tiến hành một nghiên cứu xây dựng đường cong IDF mưa cho khu vực sông $\mathrm{Vu}$ Gia-Thu Bồn trong bối cảnh $\mathrm{BĐKH}$, dựa trên chuỗi dữ liệu mưa ngày. Để tiến hành nghiên cứu này, nhóm tác giả đã sử dụng dữ liệu mưa lịch sử từ mô hình RegCM4 theo kịch bản RCP4.5 và $\mathrm{RCP} 8.5$ với độ phân giải lưới $10 \mathrm{~km}$ x $10 \mathrm{~km}$. Các kết quả nghiên cứu chỉ ra rằng, mưa có xu hướng tăng đáng kể từ 10-30\% đối với kịch bản RCP4.5 và RCP8.5. Cụ thể, mưa 1,2 và 3 ngày cực đại đã ghi nhận được sự gia tăng từ 30-300 mm/ngày theo nghiên cứu này.

Trong những năm gần đây, khu vực BĐCM đã ghi nhận xuất hiện nhiều hiện tượng thời tiết cực đoan như mưa lớn gây ngập lụt $[7,15]$. Cụ thể, ngày 3 tháng 9 năm 2018 một cơn mưa lớn kéo dài 3 hơn giờ đã khiến các tuyến đường nội đô TP. Cà Mau như Hùng Vương, Nguyễn Trãi, Nguyễn Tất Thành, Phan Ngọc Hiển, Nguyễn Công Trứ, Nguyễn Đình Chiểu và Ngô Quyền bị ngập với độ sâu ngập lên đến $50 \mathrm{~cm}$ [7-15]. Một sự kiện mưa nặng khác xuất hiện vào ngày 09/09/2019 được giới chuyên môn nhận định do ảnh hưởng của gió mùa Tây Nam hoạt động mạnh đã gây ngập cho nhiều khu vực trên địa bàn tỉnh Cà Mau [15]. Cơn mưa này có thời gian kéo dài và cường độ lớn kèm giông lốc đã gây ngập cục bộ nhiều nơi trong khu vực BĐCM gây ảnh hưởng đến hoạt động sản xuất, giao thông và công trình thủy 
lợi cũng bị ảnh hưởng nghiêm trọng [7-15]. Năm 2010 vừa qua, ngày 10 tháng 3 trên địa bàn tỉnh Cà Mau đã xuất hiện một cơn mưa kéo dài khoảng 2 giờ với lượng mưa đo được tại trạm Cà Mau lên đế 75,9mm. Cơn mưa này đã gây ngập nhiều tuyến đường tại một số huyện thị như huyện Cái Nước và trung tâm TP. Cà Mau [15]. Gần đây nhất, ngày 20 tháng 10 năm 2020 một cơn mưa lớn xuất hiện đã gây ngập nặng nhiều khu vực sản xuất nông nghiệp thuộc BĐCM như huyện Vĩnh Lợi, Hòa Bình, Phước Long, TP. Bạc Liêu, TP. Sóc Trăng, huyện Cù Lao Dung [15].

Từ những sự kiện mưa gây ngập xuất hiện ngày một thường xuyên hơn tạo khu vực $\mathrm{BĐCM}$ gây ảnh hưởng đến các hoạt động của người dân, nghiên cứu này vì vậy được tiển hành để xây dựng đường cong IDF mưa nhằm xác định chu kỳ lặp lại của một sự kiện mưa cực đoan cho khu vực $\mathrm{BĐCM}$ dựa trên phầm mềm CumFreq và mục tiêu xa hơn mà nghiên cứu hướng đến là xây dựng bản đồ số cảnh báo ngập lụt cho khu vực, góp phần hỗ trợ phòng tránh các rủi ro tiềm ẩn do các sự kiện mưa cực đoan gây ra.

\section{Phương pháp nghiên cứu}

\subsection{Khu vục nghiên cúu}

Bán đảo Cà Mau được biết đến là một vùng đất trũng thấp nằm ở cực nam của Việt Nam,

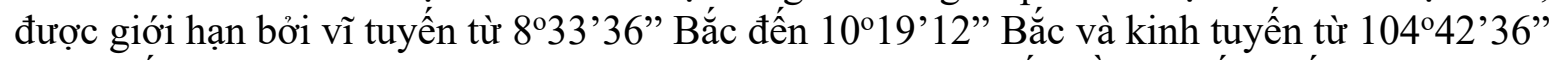
Đông đến $106^{\circ} 14^{\prime} 24^{\prime}$ ”ông (Hình 1$)$. BĐCM có địa hình thấp dần từ Bắc xuống Nam và từ Đông sang Tây với độ cao trung bình dao động từ $0,5 \mathrm{~m}$ đến $1,5 \mathrm{~m}[3,16]$. Do vị trí địa lý nằm hạ lưu sông Mekong nên chế độ thủy động lực của BĐCM chịu sự tác động của dòng chảy từ thượng nguồn sông Mekong và chế độ bán nhật triều Biển Đông, nhật triều từ Biển Tây [3, 17-18]. Nằm trong khu vực nhiệt đới gió mùa, BĐCM chịu sự chi phối của hai mùa gió Đông Bắc và Tây Nam, mưa trung bình hàng năm của khu vực cao hơn so với các khu vực khác của Việt Nam và 90\% lượng mưa năm tập trung vào mùa mưa [19].

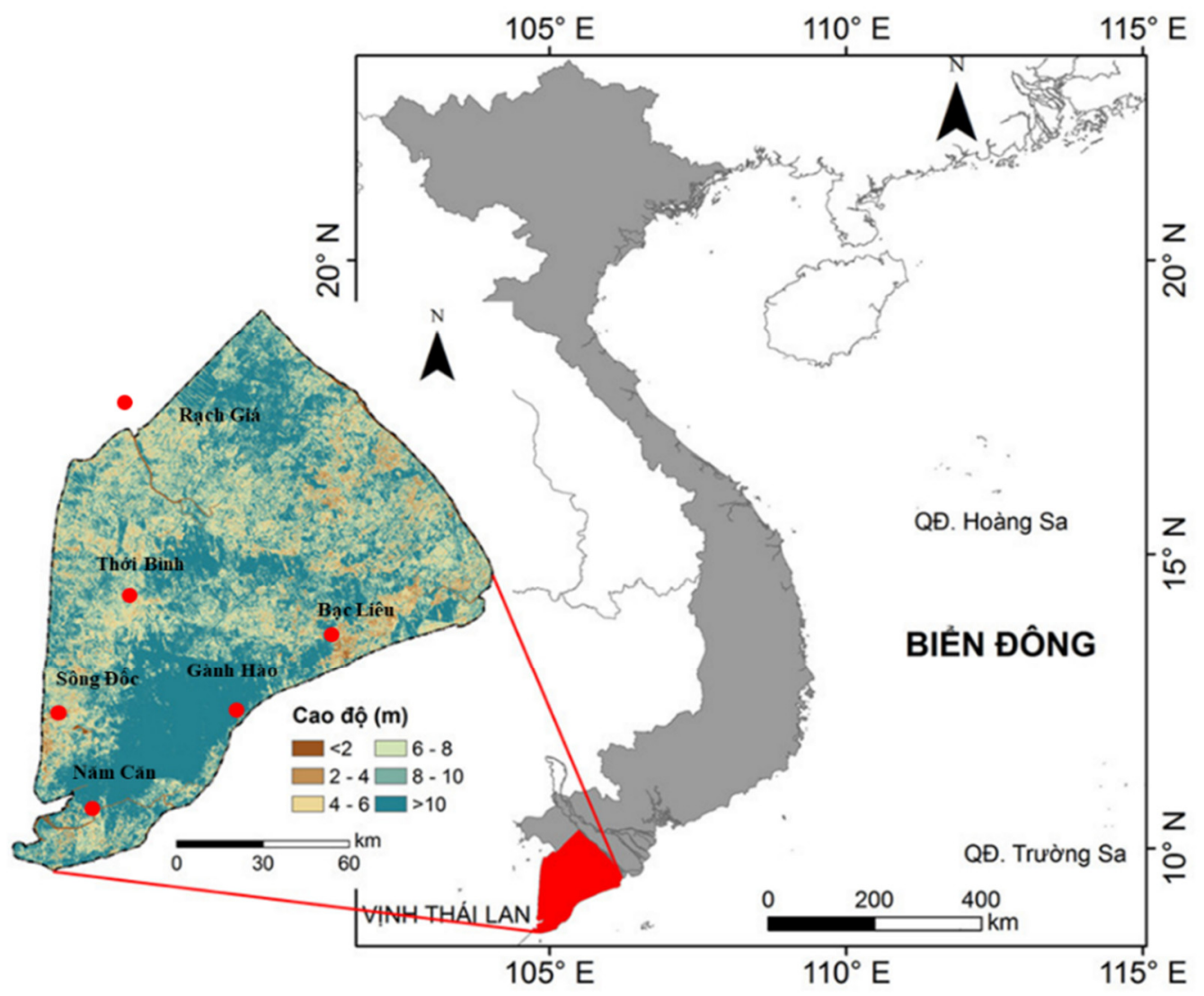

Hình 1. Bản đồ khu vực nghiên cứu với các trạm quan trắc mưa. 


\subsection{Phuơng pháp nghiên cứu}

\subsubsection{Thẩm định chất lượng chuỗi dữ liệu}

Thẩm định chất lượng chuỗi dữ liệu là một bước quan trọng trước khi tiến hành sử dụng chuỗi dữ liệu đó cho một nghiên cứu cụ thể [20]. Chất lượng một chuỗi dữ liệu chịu ảnh hưởng từ điều kiện địa hình, yếu tố khí tượng, thủy văn và mồi trường. Bên cạnh đó, việc thay đổi thiết bị quan trắc, hay thiết bị quan trắc bị hỏng cũng là một trong những nguyên nhân làm ảnh hưởng đến chất lượng của chuỗi dữ liệu [21-23]. Trong nghiên cứu này, hai phương pháp thẩm định chất lượng chuỗi dữ liệu là Pettitt và SNHT-Standard Normal Homogeinity Test được xem xét áp dụng đánh giá chất lượng chuỗi dữ liệu mưa hàng ngày tại 07 trạm thuộc khu vực nghiên cứu.

Pettitt là một phương pháp thống kê được xây dựng cho mục đích thẩm định tính đồng nhất của chuỗi dữ liệu khí tượng, thủy văn và môi trường [23]. Cụ thể, phương pháp Pettitt giúp xác định sự gián đoạn tại một vị trí bên trong chuỗi dữ liệu thông qua biểu thức toán học. Biểu thức toán học xác định sự gián đoạn của phương pháp Pettitt được cho bởi biểu thức sau:

$$
\mathrm{Xy}=\max \left|X_{k}\right|(\text { với } 1 \leq \mathrm{y}<\mathrm{n})
$$

Trong đó: giá trị cực đại $\mathrm{X}_{\mathrm{k}}$ là dữ liệu gián đoạn tại năm $\mathrm{y}$.

Với $\mathrm{X}_{\mathrm{k}}$ trong biểu thức (1) được xác định theo biểu thức (2)

$$
\mathrm{X}_{\mathrm{k}}=2 * \sum_{\mathrm{i}=1}^{\mathrm{k}} \mathrm{r}_{\mathrm{i}}-\mathrm{k}(\mathrm{n}+1) ; \mathrm{k}=1,2, \ldots, \mathrm{n}
$$

Trong đó $\mathrm{r}_{\mathrm{i}}$ là đại diện cho bậc tăng dần của chuỗi dữ liệu theo thời gian, $\mathrm{r}_{1}, \mathrm{r}_{2}, \mathrm{r}_{3}, \ldots, \mathrm{r}_{\mathrm{n}}$.

SNHT là một phương pháp thống kê được Alexanderson xây dựng cho mục đích so sánh giá trị trung bình giữa $\mathrm{v}$ năm đầu tiên với $(\mathrm{n}-\mathrm{v})$ năm cuối của chuỗi dữ liệu quan trắc. Nói cách khác, phương pháp này giúp kiểm tra đồng nhất ở phần đầu và cuối của chuỗi dữ liệu quan trắc được xét [23].

Biểu thức kiểm tra tính đồng nhất SNHT được xác định như sau:

$$
\begin{aligned}
& T_{v}=v \bar{z}_{1}^{2}+(n-v) \bar{z}_{2}^{2}, \mathrm{v}=1,2, \ldots, \mathrm{n} \\
\bar{z}_{1}= & \frac{1}{v} \sum_{i=1}^{v}\left(q_{i}-\bar{q}\right) / s \\
\bar{z}_{2}= & \frac{1}{n-v} \sum_{i=v+1}^{n}\left(q_{i}-\bar{q}\right) / s
\end{aligned}
$$

Trong đó q là chuỗi dữ liệu (với $1,2, \ldots, \mathrm{n}$ dữ liệu); $q_{i}$ giá trị của mỗi phần tử trong chuỗi dữ liệu; $\bar{q}$ là giá trị trung bình của chuỗi dữ liệu, $\mathrm{T}_{\mathrm{v}}$ là chỉ số thống kê theo năm v.

Trong trường hợp số liệu $\mathrm{v}$ năm được xác định không đồng nhất khi đạt giá trị cực đại $\mathrm{T}_{\mathrm{v}}$ [23]:

$$
T_{o}=\max _{1 \leq v \leq n}\left\{T_{v}\right\}
$$

Trong trường hợp nghiên cứu này, chuỗi dữ liệu mưa hàng ngày được thẩm định chất lượng dựa vào phương pháp Pettitt và SNHT, với mức ý nghĩa $\alpha \leq 0,05$. Điều đó có nghĩa là chuỗi dữ liệu mưa tại một trạm bất kỳ thuộc khu vực nghiên cứu được xem là đồng nhất nếu giá trị thẩm định chất lượng (giá trị $\mathrm{p}$ ) thu được lớn hơn giá trị của $\alpha=0,05$ ngược lại chuỗi dữ liệu mưa quan trắc sẽ bị nghi ngờ về tính đồng nhất hay được xem là gián đoạn [23].

\subsubsection{Chuyển đổi thời đoạn mưa}

Để tiến hành xây dựng đường cong IDF mưa, hầu hết các nghiên cứu đều sử dụng dữ liệu mưa đầu vào có thời đoạn ngắn quy mô dưới ngày [24]. Đối với các nghiên cứu có liên quan đến chuyển đổi thời đoạn mưa $[12,25]$, biểu thức (7) thường được lựa chọn để chuyển đổi thời đoạn mưa ngày sang quy mô mưa dưới ngày. Do đó, biểu thức $(7)$ được sử dụng trong nghiên cứu này để chuyển đổi dữ liệu mưa quy mô ngày sang các thời đoạn quy mô dưới ngày. Vì hầu hết các chuỗi dữ liệu mưa thu thập được đều có quy mô ngày. 


$$
\mathrm{I}_{d}=\mathrm{I}_{D} \sqrt[\eta]{\frac{d}{D}}
$$

Trong đó $\mathrm{I}_{\mathrm{d}}(\mathrm{mm})$ là lượng mưa ứng với thời đoạn mưa cần chuyển đổi, $\mathrm{I}_{\mathrm{D}}(\mathrm{mm})$ là lượng mưa thời đoạn 24 giờ, $\eta$ là hàm mũ bằng $1 / 3, \mathrm{~d}$ (giờ) là thời đoạn mưa cần chuyển đổi, $\mathrm{D}$ là thời đoạn mưa 24 giờ, $\mathrm{d} / \mathrm{D}$ là tỷ số giữa 2 thời đoạn mưa khác nhau, dấu "=" đại diện cho sự bằng nhau về phân bố xác suất của 2 vế [12, 25].

\subsubsection{Xây dựng đường cong IDF mưa}

Đường cong IDF mưa được xây dựng trong nghiên cứu này dựa trên phần mềm CumFreq [26]. Phần mềm CumFreq được phát triển bởi Viện Cải Thiện và Cải Tạo Đất Quốc Tế, là một chương trình hoàn toàn miễn phí dùng tính toán tần suất tích lũy cũng như chu kỳ lặp lại của yếu tố khí tượng, thủy văn và môi trường [27]. Trong nghiên cứu này, phần mềm CumFreq được áp dụng tính toán tần suất tích lũy, chu kỳ lặp lại và thời đoạn của chuỗi dữ liệu mưa tại các trạm quan trắc mưa khu vực BĐCM.

Trong phần mềm CumFreq, ba hàm phân bố Gumbel, GEV và Log-Pearson III thường được sử dụng để xác định đường cong IDF mưa $[23,26]$. Trong nghiên cứu này, hàm GEV được lựa chọn xây dựng đường cong IDF mưa cho khu vực BĐCM thông qua các đánh giá sơ bộ về khả năng áp dụng của nó so với hàm phân bố khác và dựa vào các kết quả nghiên cứu từ các công trình đã công bố $[7,11-12,24]$ cho các khu vực thuộc Việt Nam.

Hàm phân bố tần suất tích lũy GEV được xây dựng như sau:

$$
F(x)=\exp \left[-\left(1+k\left(\frac{x-\mu}{\sigma}\right)\right)^{-\frac{1}{k}}\right]
$$

Trong đó $\mathrm{F}(\mathrm{x})$ biểu thị hàm phân phối $\mathrm{GEV}, \sigma$ là tham số tỷ lệ với $\sigma>0$ xác định độ lệch hai phía so với tham số vị trí, $\mathrm{k}$ là tham số hình dạng chi phối hình dáng của phân phối xác suất, $\mu$ là tham số vị trí, phụ thuộc vào thời gian và được xác định thông qua mối liên hệ trong biểu thức $(9)[7,28]$.

$$
\mu(t)=\mu_{1}(t)+\mu_{0}
$$

Trong đó $t$ là thời gian, $\mu_{1}$ và $\mu_{0}$ là tham số chặn và dốc $[7,28]$.

Hàm phân phối GEV được đánh giá là một hàm phân phối linh hoạt, nó chứa bên trong các tham số vị trí $(\mu)$, quy mô $(\sigma)$ và hình dạng $(\mathrm{k})$. Chính vì vậy, hàm phân phối này được lựa chọn áp dụng rộng rãi trong các nghiên cứu có liên quan bởi [7,29].

Quy trình các bước tiến hành xây dựng đường cong IDF mưa cho khu vực $\mathrm{B} Đ \mathrm{CM}$ được minh họa ở Hình 2.

Cụ thể các bước tiến hành nghiên cứu này được thực hiện như sau:

Phân tích sơ bộ chuỗi dữ liệu mưa quan trắc đầu vào;

Đánh giá chất lượng dữ liệu mưa lịch sử thông qua phương pháp Pettitt và SNHT;

Chuyển đổi dữ liệu mưa quy mô ngày về quy mô dưới ngày bởi dụng biểu thức (7);

Phân tích, đánh giá khả năng sử dụng các hàm phân bố GEV, Gumbel và Log-Pearson thiết lập hàm phân phối tần suất tích lũy $(\mathrm{CDF})$ mưa;

Xây dựng đường cong IDF mưa dựa trên hàm phân phối tần suất tích lũy CDF.

Trong nghiên cứu này, các đường cong IDF mưa được xây dựng tương ứng với các khoảng thời gian $0,25,0,5,1,1,5,2,3,6,8$ và 12 giờ.

\subsubsection{Dữ liệu đầu vào phục vụ nghiên cứu}

Chuỗi số liệu mưa hàng ngày tại các trạm quan trắc Gành Hào, Năm Căn, Sông Đốc, Thới Bình, Rạch Giá và Bạc Liêu được thu thập từ Tổng Cục Khí tượng Thủy văn và Phân Viện Khoa học Khí tượng Thủy văn và Biến đổi khí hậu (SIHYMECC) trong giai đoạn 1984-2017. Qua phân tích sơ bộ cho thấy, lượng mưa trung bình năm tại các trạm thuộc khu vực $\mathrm{BĐCM}$ đạt từ $1885,4 \mathrm{~mm}$ đến $2356,0 \mathrm{~mm}$ và lượng mưa một ngày lớn nhất dao động trong khoảng từ 0 đến 224,6 mm (Bảng 1). 


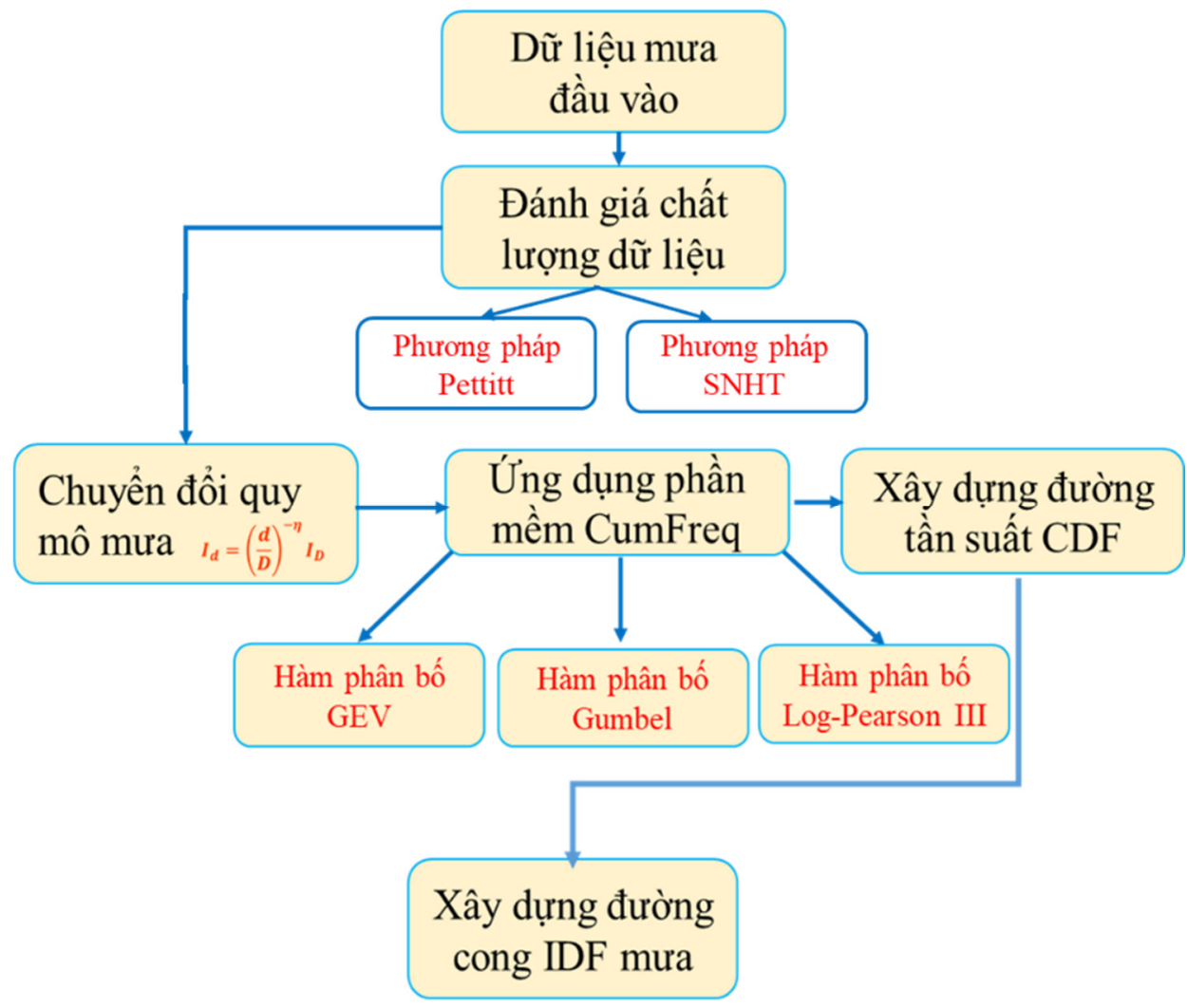

Hình 2. Quy trình tiến hành xây dựng đường IDF mưa cho khu vực BĐCM.

Bảng 1. Các thông tin và đặc trưng thống kê của 07 trạm đo mưa khu vực nghiên cứu.

\begin{tabular}{|c|c|c|c|c|c|c|c|c|}
\hline \multirow[b]{2}{*}{ Trạm } & \multicolumn{2}{|c|}{ Tọa độ } & \multirow{2}{*}{$\begin{array}{c}\text { Mưa năm } \\
\text { trung bình } \\
\quad(\mathbf{m m})\end{array}$} & \multirow{2}{*}{$\begin{array}{l}\text { Mưa ngày } \\
\text { trung bình } \\
(\mathrm{mm})\end{array}$} & \multirow{2}{*}{$\begin{array}{c}\text { Mưa ngày } \\
\text { lớn nhất } \\
(\mathbf{m m})\end{array}$} & \multicolumn{2}{|c|}{ Giai đoạn } & \multirow{2}{*}{$\begin{array}{c}\text { Khoảng } \\
\text { thời gian } \\
\text { (năm) }\end{array}$} \\
\hline & Vĩ độ & Kinh độ & & & & Từ & Đến & \\
\hline Bạc Liêu & 105,71 & 9,28 & 1949,7 & 39,1 & 203,7 & 1984 & 2017 & 34 \\
\hline Gành Hào & 105,42 & 9,03 & 1885,4 & 41,1 & 224,6 & 1984 & 2017 & 34 \\
\hline Năm Căn & 105,07 & 8,75 & 2339,3 & 48,2 & 246,4 & 1987 & 2017 & 31 \\
\hline Thới Bình & 105,09 & 9,35 & 2337,0 & 46,7 & 184,0 & 1984 & 2017 & 34 \\
\hline Sông Đốc & 104,83 & 9,04 & 2261,6 & 47,5 & 239,6 & 1984 & 2017 & 34 \\
\hline Rạch Gía & 105,07 & 10,00 & 2168,1 & 44,4 & 220,3 & 1984 & 2017 & 34 \\
\hline
\end{tabular}

\section{Kết quả và thảo luận}

\section{1. Đánh giá chất lượng chuỗi dũ liệu mưa}

Kết quả thẩm định chất lượng chuỗi dữ liệu mưa tại 06 trạm quan trắc thuộc khu vực nghiên cứu được trình bày ở Bảng 2 . Qua kết quả thẩm định dựa trên phương pháp Pettitt và SNHT cho thấy, giá trị $\mathrm{p}$ thu được đối với các trạm Gành Hào, Thới Bình, Năm Căn, Bạc Liêu và Rạch Giá dao động trong khoảng 0,418-0,943 (Bảng 2). Trong khi, tại trạm Sông Đốc giá trị $p$ tính được là 0,004 (đối với phương pháp Pettitt) và 0,049 (đối với phương pháp SNHT). Với mức ý nghĩa $\alpha \leq 0,05$, chuỗi dữ liệu mưa trạm Sông Đốc không đồng nhất (Hình 3), trong khi các trạm còn lại có tính đồng nhất bởi giá trị p lớn hơn mức ý nghĩa. Do đó, chuỗi dữ liệu mưa trạm Sông Đốc không được xem xét cho xây dựng đường cong IDF mưa tại trạm này. 
Bảng 2. Kết quả thẩm định chất lượng chuỗi dữ liệu mưa tại các trạm quan trắc mưa khu vực BĐCM.

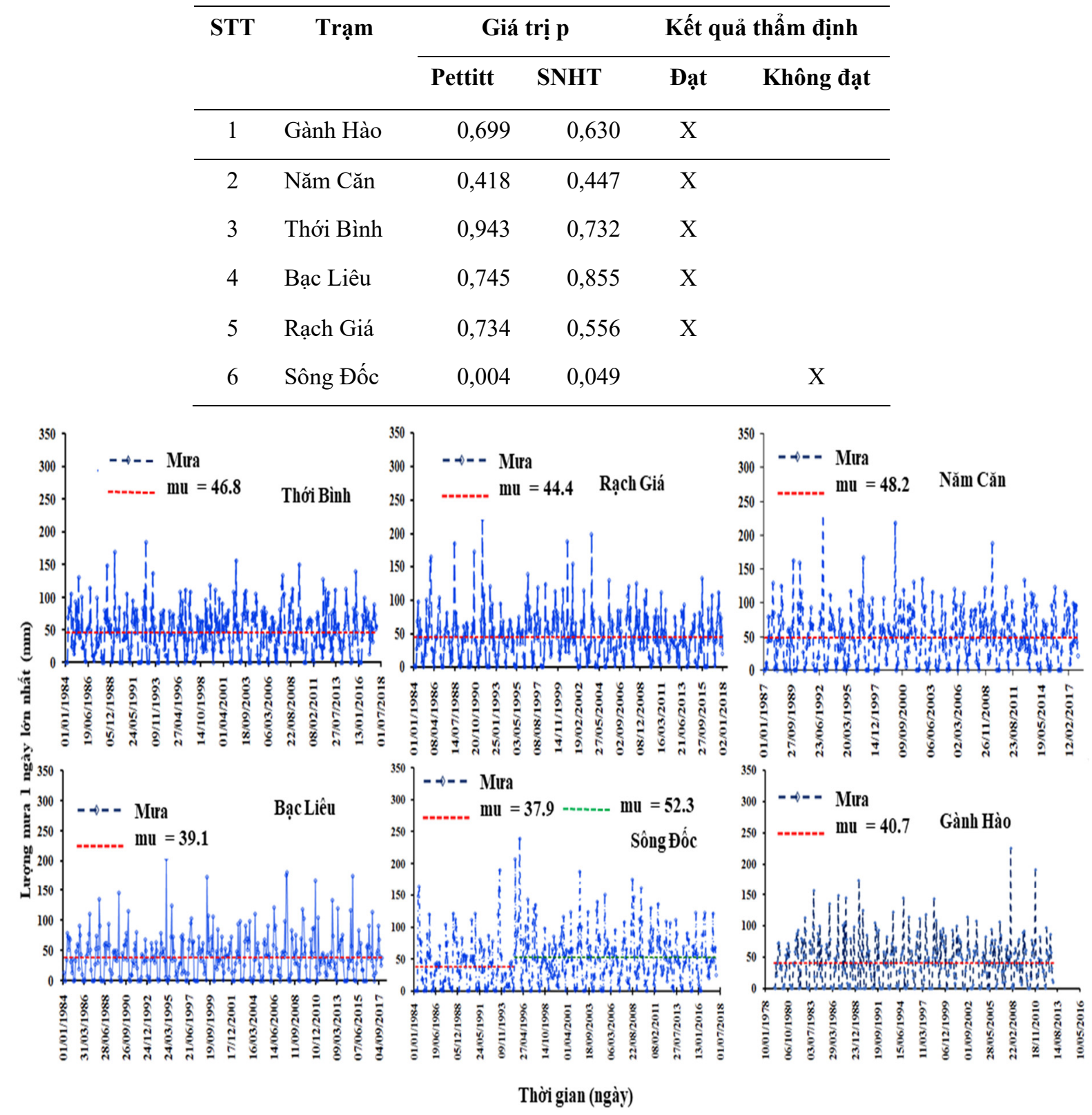

Hình 3. Thẩm định chất lượng chuỗi dữ liệu mưa tại các trạm thuộc khu vực BĐCM.

\subsection{Xây dựng đường cong IDF mưa}

Đường cong IDF mưa xây dựng cho 05 trạm đo mưa thuộc khu vực $\mathrm{BĐCM}$ được trình bày ở Hình 4 . Kết quả tính toán cho thấy, với thời đoạn ngắn 0,25 giờ, cường độ mưa có thể dao động trong khoảng từ 33,9 mm/giờ đến 42,8mm/giờ đối với chu kỳ lặp lại 2 năm trong khi với chu kỳ lặp lại 100 năm, cường độ mưa tại các trạm thuộc khu vực nghiên cứu dao động trong khoảng từ 114,8 mm/giờ đến $215,2 \mathrm{~mm}$ /giờ (Bảng 3 ). Tương tự với các thời đoạn mưa từ 0,5 đến 8 giờ, cường độ mưa tại các trạm dao động trong khoảng từ $21,4 \mathrm{~mm} / \mathrm{giờ} \mathrm{đến}$ $135,7 \mathrm{~mm} /$ giờ và $3,4 \mathrm{~mm} /$ giờ đến $21,4 \mathrm{~mm} /$ giờ. Nhìn chung, trên toàn khu vực nghiên cứu, cường độ mưa lớn nhất xảy ra ở chu kỳ lặp lại 100 năm tức là tần suất lặp lại $1 \%$ tại tất cả thời đoạn mưa khác nhau, dao động từ $8,7 \mathrm{~mm} /$ giờ (thời đoạn $12 \mathrm{~h}$, đối với trạm Thới Bình) đến 215,2 mm/giờ (thời đoạn 15 phút, đối với trạm Năm Căn); với trạm Bạc Liêu, Rạch Giá và Gành Hào cường độ mưa 15 phút lần lượt ghi nhận được 178,2 mm/giờ, 192,4mm/giờ và 196,3 mm/giờ (Bảng 3). 

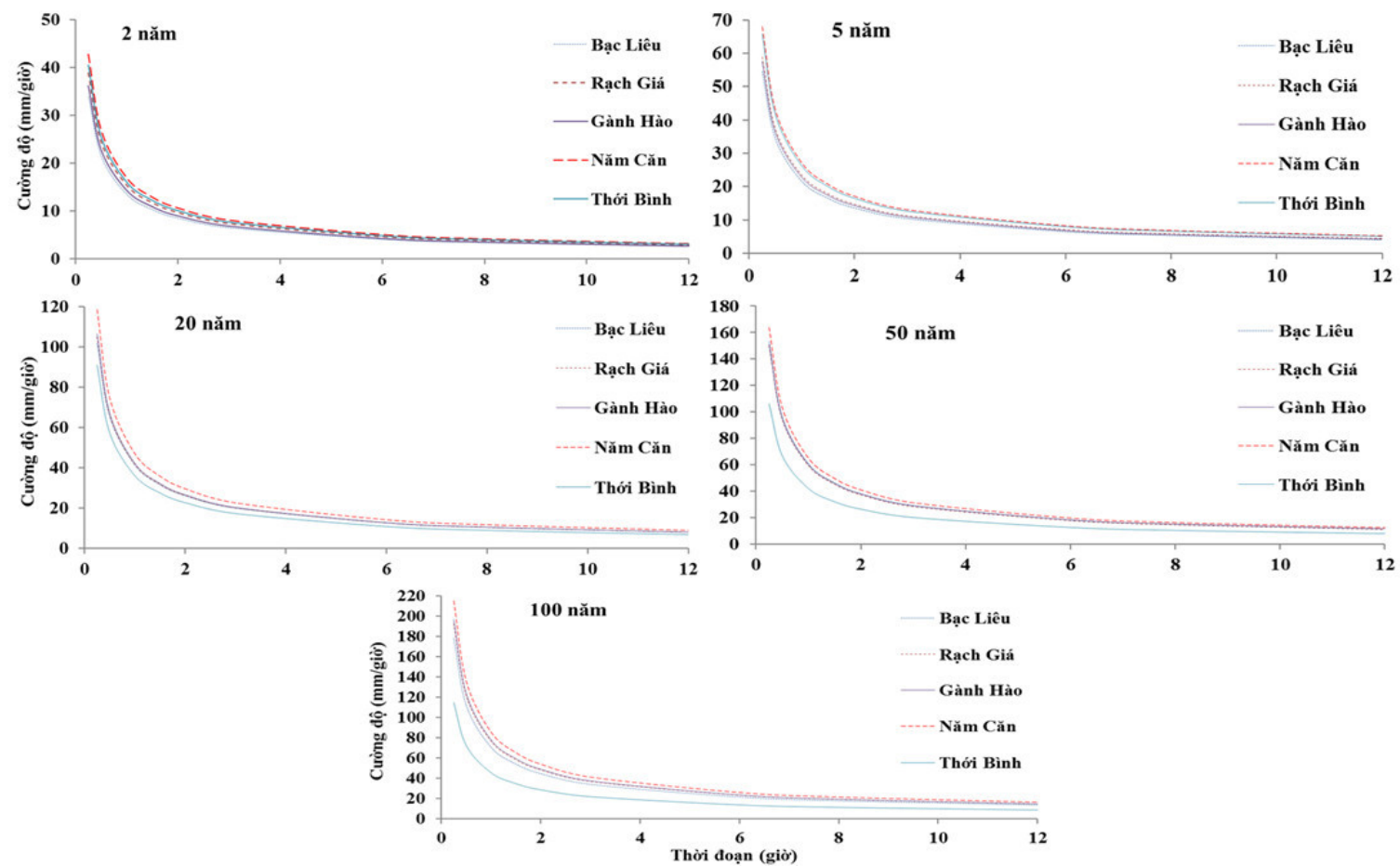

Hình 4. Các đường cong thời đoạn-cường độ-tần suất mưa xây dựng cho các trạm thuộc khu vực BĐCM với chu kỳ lặp lại từ 2 đến 100 năm và thời đoạn từ 0,25 giờ đến 12 giờ.

Bảng 3. Kết quả phân tích cường độ mưa theo các thời đoạn và chu kỳ lặp tại các trạm.

\begin{tabular}{|c|c|c|c|c|c|c|c|c|c|}
\hline \multirow{2}{*}{ Trạm } & \multicolumn{9}{|c|}{ Các thời đoạn mưa (giờ) } \\
\hline & $\mathbf{0 , 2 5}$ & 0,5 & 1 & 1,5 & 2 & 3 & 6 & 8 & 12 \\
\hline \multicolumn{10}{|c|}{ Chu kỳ lạp: 2 năm } \\
\hline Bạc Liêu & 33,9 & 21,4 & 13,5 & 10,3 & 8,5 & 6,5 & 4,1 & 3,4 & 2,6 \\
\hline Rạch Giá & 38,8 & 24,4 & 15,4 & 11,7 & 9,7 & 7,4 & 4,7 & 3,9 & 2,9 \\
\hline Gành Hào & 36,2 & 22,8 & 14,4 & 11,0 & 9,1 & 6,9 & 4,4 & 3,6 & 2,7 \\
\hline Năm Căn & 42,8 & 27,0 & 17,0 & 13,0 & 10,7 & 8,2 & 5,2 & 4,3 & 3,2 \\
\hline Thới Bình & 40,5 & 25,5 & 16,1 & 12,3 & 10,1 & 7,7 & 4,9 & 4,0 & 3,1 \\
\hline \multicolumn{10}{|c|}{ Chu kỳ lạp: 5 năm } \\
\hline Bạc Liêu & 54,6 & 34,4 & 21,7 & 16,5 & 13,7 & 10,4 & 6,6 & 5,4 & 4,1 \\
\hline Rạch Giá & 59,0 & 37,1 & 23,4 & 17,9 & 14,7 & 11,2 & 7,1 & 5,9 & 4,5 \\
\hline Gành Hào & 57,5 & 36,2 & 22,8 & 17,4 & 14,4 & 11,0 & 6,9 & 5,7 & 4,4 \\
\hline Năm Căn & 68,1 & 42,9 & 27,0 & 20,6 & 17,1 & 13,0 & 8,2 & 6,8 & 5,2 \\
\hline Thới Bình & 65,8 & 41,5 & 26,1 & 19,9 & 16,5 & 12,6 & 7,9 & 6,5 & 5,0 \\
\hline \multicolumn{10}{|c|}{ Chu kỳ lạp: 20 năm } \\
\hline Bạc Liêu & 101,8 & 65,6 & 41,3 & 31,5 & 26,0 & 19,9 & 12,5 & 10,3 & 7,9 \\
\hline Rạch Giá & 105,0 & 66,1 & 41,6 & 31,8 & 26,2 & 20,0 & 12,6 & 10,4 & 7,9 \\
\hline Gành Hào & 106,6 & 67,1 & 42,3 & 32,3 & 26,6 & 20,3 & 12,8 & 10,6 & 8,1 \\
\hline Năm Căn & 118,6 & 74,7 & 47,1 & 35,9 & 29,7 & 22,6 & 14,3 & 11,8 & 9,0 \\
\hline Thới Bình & 91,1 & 57,4 & 36,2 & 27,6 & 22,8 & 17,4 & 11,0 & 9,0 & 6,9 \\
\hline \multicolumn{10}{|c|}{ Chu kỳ lạp: 50 năm } \\
\hline Bạc Liêu & 153,1 & 96,3 & 60,8 & 46,4 & 38,2 & 29,2 & 18,4 & 15,2 & 11,6 \\
\hline Rạch Giá & 149,8 & 94,3 & 59,5 & 45,4 & 37,5 & 28,6 & 18,0 & 14,9 & 11,4 \\
\hline Gành Hào & 151,4 & 95,3 & 60,0 & 45,8 & 37,8 & 28,9 & 18,2 & 15,0 & 11,5 \\
\hline Năm Căn & 163,9 & 103,1 & 65,0 & 49,6 & 41,0 & 31,2 & 19,7 & 16,3 & 12,4 \\
\hline Thới Bình & 106,3 & 67,0 & 42,2 & 32,2 & 26,6 & 20,3 & 12,8 & 10,6 & 8,1 \\
\hline \multicolumn{10}{|c|}{ Chu kỳ lăp: 100 năm } \\
\hline Bạc Liêu & 178,2 & 112,0 & 70,6 & 54,0 & 44,5 & 33,9 & 21,4 & 17,6 & 13,5 \\
\hline Rạch Giá & 192,4 & 121,2 & 76,5 & 58,3 & 48,2 & 36,7 & 23,2 & 19,1 & 14,6 \\
\hline Gành Hào & 196,3 & 123,5 & 77,8 & 59,4 & 49,0 & 37,4 & 23,6 & 19,5 & 14,9 \\
\hline Năm Căn & 215,2 & 135,7 & 85,5 & 65,2 & 53,9 & 41,1 & 25,9 & 21,4 & 16,3 \\
\hline Thới Bình & 114,8 & 72,3 & 45,6 & 34,8 & 28,7 & 21,9 & 13,8 & 11,4 & 8,7 \\
\hline
\end{tabular}




\section{Kết luận}

Nghiên cứu đã tiến hành xây dựng đường cong cường độ-thời đoạn-tần suất mưa theo các thời đoạn từ 0,25 đến 12 giờ ứng với các chu kỳ lặp lại từ 2 đến 100 năm cho khu vực bán đảo Cà Mau. Các kết quả tính toán thu được cho thấy cơn mưa có lượng mưa từ $60,0 \mathrm{~mm}$ trở lên xảy ra trong thời đoạn dưới 3 giờ sẽ gây ngập cục bộ một số khu vực từ $0,7-1,0 \mathrm{~m}$. Trong khi đó, với sự các sự kiện mưa cực đoan có cường độ lên đến $215,2 \mathrm{~mm} /$ giờ ứng với chu kỳ lặp lại 100 năm, độ sâu và phạm vi ngập chắc chắn sẽ nghiêm trọng hơn đối với công trình dân dụng như đường giao thông, công trình thủy lợi, các khu dân cư nằm trong vùng trũng.

Các kết quả xây dựng đường cong cường độ-thời đoạn-tần suất tương ứng với các thời đoạn và chu kỳ lặp lại rất cần thiết để hỗ trợ thông tin trong công tác xây dựng, nâng cấp hệ thống thoát nước, quy hoạch thủy lợi góp phần hạn chế các rủi ro từ các sự kiện mưa cực đoan có xu hướng xuất hiện ngày một gia tăng đối với khu vực bán đảo Cà Mau.

Đóng góp của tác giả: Xây dựng ý tưởng nghiên cứu: H.C.T., D.T.A.; Lựa chọn phương pháp nghiên cứu: H.C.T., D.T.A.; Viết bản thảo bài báo: H.C.T., D.T.A.; Chỉnh sửa bài báo: H.C.T., D.T.A.

Lời cảm ơn: Các tác giả xin chân thành cảm ơn các phản biện đã đóng góp ý kiến hữu ích, giúp các tác giả hoàn thiện bản thảo này.

Lời cam đoan: Tập thể tác giả cam đoan bài báo này là công trình nghiên cứu của tập thể tác giả, chưa được công bố ở đâu, không được sao chép từ những nghiên cứu trước đây; không có sự tranh chấp lợi ích trong nhóm tác giả.

\section{Tài liệu tham khảo}

1. IPCC. Climate Change 2013: The Physical Science Basis. Contribution of Working Group I to the Fifth Assessment Report of the Intergovernmental Panel on Climate Change. Stocker, T.F.; Qin, D.; Plattner, G.K.; Tignor, M.; Allen, S.K.; Boschung, J.; Nauels, A.; Xia, Y.; Bex, V.; Midgley, P.M. (eds.). Cambridge University Press, Cambridge, United Kingdom and New York, NY, USA, 2013, pp. 1535. https://doi.org/10.1017/CBO9781107415324.

2. Bộ Tài nguyên và Môi trường. Kịch bản Biến đổi khí hậu và nước biển dâng cho Việt Nam. Nhà xuất bản Tài nguyên - Môi trường và Bản đồ Việt Nam, 2016.

3. Thuy, N.N; Anh, H.H. Vulnerability of rice production in Mekong River Delta under impacts from floods, salinity and climate change. Int. J. Adv. Sci. Eng. Inf. Tech. 2015, 5(4), 272-279.

4. Vu, D.T.; Yamada, T.; Ishidaira, H. Assessing the impact of sea level rise due to climate change on seawater intrusion in Mekong delta, Vietnam. Water Sci. Tech. 2018, 77(6), 1632-1639. https://doi.org/10.2166/wst.2018.038.

5. Walanus, A.; Cebulska, M.; Twardosz, R. Long-term variability pattern of monthly and annual atmospheric precipitation in the Polish Carpathian mountains and their foreland (1881-2018). Pure Appl. Geophys. 2021, 178, 633-650. https://doi.org/10.1007/s00024-021-02663-9.

6. Lee, S.K.; Dang, T.A. Extreme rainfall trends over the Mekong Delta under the impacts of climate change. Int. J. Clim. Change Strategies Manage. 2020, 12(5), 639-652. https://doi.org/10.1108/IJCCSM-04-2020-0032.

7. Dang, T.A. Simulating rainfall IDF curve for flood warnings in the Ca Mau coastal area under the impacts of climate change. Int. J. Clim. Change Strategies Manage. 2020, 12(5), 705-715. https://doi.org/10.1108/IJCCSM-06-2020-0067.

8. Akpen, G.D.; Aho, M.I.; Ojo, O.G. Rainfall Intensity - Duration - Frequency (IDF) models for Makurdi, Nigeria. Int. J. Sci. Eng. Res. 2016, 7(5), 838-849. ISSN 2229-5518. 
9. Boudou, M.; Danière, B.; Lang, M. Assessing changes in urban flood vulnerability through mapping land use from historical information. Hydrol. Earth Syst. Sci. 2016, 20, 161-173. https://doi.org/10.5194/hess-20-161-2016.

10. Rodríguez, R.; Navarro, X.; Casas, C.; Ribalaygua, J.; Russo, B.; Pouget, L.; Redano, A. Influence of climate change on IDF curves for the metropolitan area of Barcelona (Spain). Int. J. Climatol. 2014, 34(3), 643-654. https://doi.org/10.1002/joc.3712.

11. Binh, L.T.H.; Aglian, V.; Umamahesh, N.V.; Rathnam, E.V. Modelling spatial variation of extreme precipitation over Ho Chi Minh City under nonstationary condition. Acta Geophys. 2019, 67, 849-861. https://doi.org/10.1007/s11600-01900295-1

12. Khiem. V.M.; Minh. T.H.; Linh. N.L. Impact of climate change on Intensity Duration - Frequency curves in Ho Chi Minh City. J. Clim. Change Sci. 2017, 3, 40-48.

13. Nội, D.T.; Long, N.L.; Tùng, H.T. Nghiên cứu đề xuất phương pháp tính lũ thiết kế công trình giao thông vùng Đông Bắc Việt Nam. Tạp chí khoa học Kỹ thuật Thủy lợi và Môi trường 2016, 53, 80-86.

14. Thanh, N.T.; Remo, L.D.A. Projected changes of precipitation IDF curves for short duration under climate change in Central Vietnam. Hydrol. 2018, 5(3), 33. https://doi.org/10.3390/hydrology5030033.

15. Ban chỉ huy Phòng chống thiên tai và Tìm kiếm cứu nạn tỉnh Cà Mau. Kế hoạch Phòng, chống thiên tai giai đoạn 2016-2020 trên địa bàn tỉnh Cà Mau, Công văn số 10/KH-PCTT, 2016.

16. Liu, J.P.; DeMaster, D.J.; Nguyen, T.T.; Saito, Y.; Nguyen, V.L.; Ta, T.K.O.; Li, $X$. Stratigraphic formation of the Mekong River Delta and its recent shoreline changes. Oceanogr. 2017, 30(3), 72-83.

17. Nhung, T.T.; Phu, L.V.; Nghi, V.V.; Bang, H.Q. Salt intrusion adaptation measures for sustainable agricultural development under climate change effects: A case of $\mathrm{Ca}$ Mau Peninsula, Vietnam. Clim. Risk Manage. 2019, 23, 88-100. https://doi.org/10.1016/j.crm.2018.12.002.

18. Son, N.T.; Chen, C.F.; Chang, N.B.; Chen, C.R.; Chang, L.Y.; Bui, X.T. Mangrove mapping and change detection in Ca Mau Peninsula, Vietnam, using landsat data and object-based image analysis. IEEE J. Sel. Top. Appl. Earth Obs. Remote Sens. 2015, 8(2), 503-510. https://doi: 10.1109/JSTARS.2014.2360691

19. Nguyen, V.L.; Ta, T.K.O.; Tateishi, M. Late Holocene depositional enviroments and coastal evolution of the Mekong River Delta, southern Vietnam. J. Asian Earth Sci. 2020, 18(4), 427-439. https://doi: 10.1016/S1367-9120(99)00076-0.

20. Valík, A.; Brazdil, R.; Zahradnicek, P.; Tolasz, R.; Fiala, R. Precipitation measurements by manual and automatic rain gauges and their influence on homogeneity of long-term precipitation series. Int. J. Clim. 2020, 41(S1), E2357E2552. https://doi: 10.1002/joc.6862.

21. San, M.; Akcay, F.; Linh, N.T.T.; Kankal, M.; Pham, Q.B. Innovative and polygonal trend analyses applications for rainfall data in Vietnam. Theor. Appl. Climatol. 2021. https://doi: 10.1007/s00704-021-03574-4.

22. Shah, N.V.; Patel, Y.S.; Dbhangaokar, P. Assessing impact of climate change on rainfall patterns of Vadodara District, Gujarat, India. J. Phys.: Conf. Ser. 2021, 1714, 012046. https://doi:10.1088/1742-6596/1714/1/012046.

23. Jing, L.N.; Tiang, S.K.; Huang, Y.F.; Noh, N.I.F.M.; Al-Mansob, R.A. Analysis of annual maximum and partial duration rainfall series. IOP Conf. Series: Earth Env. Sci. 2021, 646, 012039. https://doi:10.1088/1755-1315/646/1/012039. 
24. Quân, N.T.; Nhi, P.T.T.; Khôi, Đ.N. Xây dựng đường cong IDF mưa cực đoan cho trạm Tân Sơn Hòa giai đoạn 1980-2015. Tạp chí phát triển khoa học và công nghệ 2017, 20(M2-2017), 73-81.

25. Nhat, L.M.; Tachikawa, Y.; Takara, K. Establishment of Intensity-Duration Fequency curves for precipitation in the monsoon area of Vietnam. Annuals Disas. Prev. Res. Inst. Kyoto Univ. 2006, 49B, 93-103.

26. Introduce to CumFreq software. http://www.waterlog.info/cumfreq.htm.

27. Al-Baldawi, T.H.K.; Alzuabidi, Z.Z.A. Extreme value analysis of maximum rainfall data in Baghdad city. Math. Stat. J. 2016, 2(3), 1-8.

28. Chen, J.; Wang, Z.; Wu, X.; Lai, C.; Chen, X. Evaluation of TMPA 3B42-V7 product on extreme precipitation estimates. Remote Sens. 2021, 13, 209. https://doi.org/ 10.3390/rs13020209.

29. Cheng, L.; Aghakouchak, A. Non-stationary extreme value analysis in a changing climate. Clim. Change 2014, 127, 353-369. https://doi.org/10.1007/s10584-014$1254-5$.

\title{
Simulating rainfall intensity-duration-frequency curve towards establishing innundation maps in Camau peninsula
}

\author{
Ho Cong Toan ${ }^{1}$, Truong An Dang ${ }^{*}$ \\ ${ }^{1}$ University of Science, Vietnam National University-Ho Chi Minh City; \\ hocongtoanhdh@gmail.com; dtan@hcmus.edu.vn
}

\begin{abstract}
In recent years, heavy rainfall events have appeared frequently in the $\mathrm{Ca} \mathrm{Mau}$ peninsula area, causing local flooding and affecting many aspects of life in the area. According to a report of the Ministry of Natural Resources and Environment, rainfall is an increase tend in intensity and frequency in the $\mathrm{Ca}$ Mau Peninsula as a part of climate variability. Heavy rainfall tends increase, which will cause the local flooding events in which has low terrain and less severe drainage systems. It is, thus, necessary to proactively prevent adverse effects from flooding events on people's lives. Therefore, the goal of the study is a) to simulate rainfall intensity-duration-frequency (IDF) curve of the extreme rainfall events using the CumFreq software for the Ca Mau Peninsula and b) toward to establish inundation maps based on the simulated data from rainfall IDF curve, contributing to proactively minimize the potential risks of flooding as well as proactively adapt the impacts of climate variability.
\end{abstract}

Keywords: Flooding; Low-lying area; Unusual rainfall; Sea level rise; Ca Mau peninsula. 